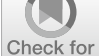

update

Cite as

Nano-Micro Lett.

(2019) 11:41

Received: 19 February 2019

Accepted: 8 April 2019

Published online: 16 May 2019

(C) The Author(s) 2019

\section{Prompt Electrodeposition of Ni Nanodots on Ni Foam to Construct a High-Performance Water-Splitting Electrode: Efficient, Scalable, and Recyclable}

\author{
Hongtao $\mathrm{Yu}^{1,2}$, Ting Quan $^{1}$, Shilin $\mathrm{Mei}^{1}{ }^{1}$ Zdravko Kochovski ${ }^{1}$, Wei Huang ${ }^{2} \bowtie$, \\ Hong Meng ${ }^{2}$, Yan $\mathrm{Lu}^{1,3} \bowtie$ \\ $\bowtie$ Wei Huang, iamwhuang@njtech.edu.cn; Yan Lu, yan.lu@helmholtz-berlin.de \\ 1 Soft Matter and Functional Materials, Helmholtz-Zentrum Berlin für Materialien und Energie, \\ Hahn-Meitner Platz 1, 14109 Berlin, Germany \\ 2 Key Lab for Flexible Electronics \& Institute of Advanced Materials, Jiangsu National Synergistic Innovation \\ Center for Advanced Materials (SICAM), Nanjing Tech University, 30 South Puzhu Road, Nanjing, \\ People's Republic of China \\ 3 Institute of Chemistry, University of Potsdam, 14467 Potsdam, Germany
}

\title{
HIGHLIGHTS
}

- Facile electrodeposition for fabricating active Ni nanodots (NiNDs) on Ni foam (NF) is shown.

- Binder- and heteroatom-free recyclable NiO/NiNDs@NF electrodes are efficiently made.

- NiO/NiNDs@NF bifunctional catalytic electrodes are used for water splitting.

ABSTRACT In past decades, Ni-based catalytic materials and electrodes have been intensively explored as low-cost hydrogen evolution reaction (HER) and oxygen evolution reaction (OER) catalysts for water splitting. With increasing demands for Ni worldwide, simplifying the fabrication process, increasing Ni recycling, and reducing waste are tangible sustainability goals. Here, binder-free, heteroatom-free, and recyclable Ni-based bifunctional catalytic electrodes were fabricated via a one-step quick electrodeposition method. Typically, active Ni nanodot (NiND) clusters are electrodeposited on $\mathrm{Ni}$ foam $(\mathrm{NF})$ in $\mathrm{Ni}\left(\mathrm{NO}_{3}\right)_{2}$ acetonitrile solution. After drying in air, $\mathrm{NiO} / \mathrm{NiND}$ composites are obtained, leading to a binder-free and heteroatom-free NiO/NiNDs@NF catalytic electrode. The electrode shows high efficiency and long-term stability for catalyzing hydrogen and oxygen evolution reactions at low overpotentials $\left({ }^{10} \eta_{\mathrm{HER}}=119 \mathrm{mV}\right.$ and

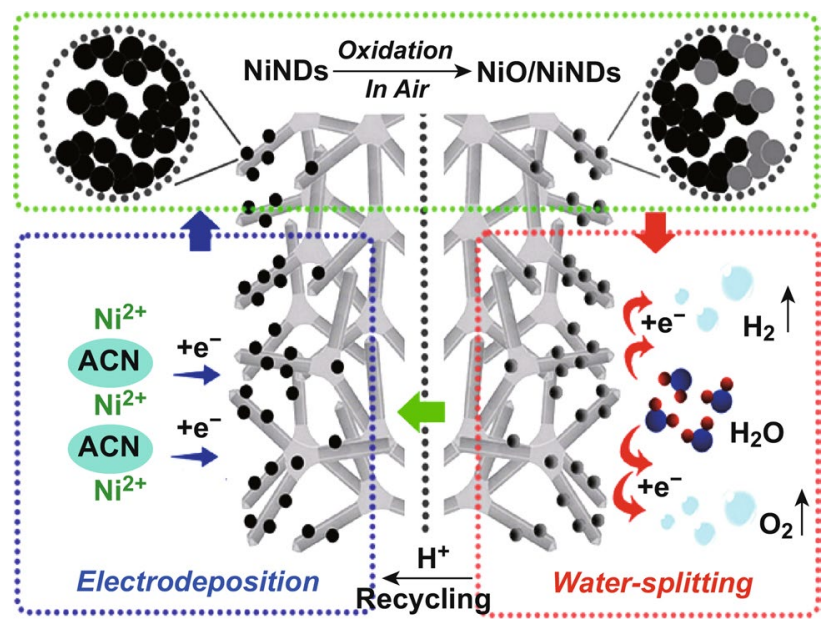
${ }^{50} \eta_{\mathrm{OER}}=360 \mathrm{mV}$ ) and can promote water catalysis at $1.70 \mathrm{~V} @ 10 \mathrm{~mA} \mathrm{~cm}^{-2}$.

More importantly, the recovery of raw materials $\left(\mathrm{NF}\right.$ and $\left.\mathrm{Ni}\left(\mathrm{NO}_{3}\right)_{2}\right)$ is quite easy because of the solubility of NiO/NiNDs composites in acid solution for recycling the electrodes. Additionally, a large-sized $\left(S \sim 70 \mathrm{~cm}^{2}\right)$ NiO/NiNDs@NF catalytic electrode with high durability has also been constructed. This method provides a simple and fast technology to construct high-performance, low-cost, and environmentally friendly Ni-based bifunctional electrocatalytic electrodes for water splitting.

KEYWORDS Electrodeposition; Ni nanodots; Bifunctional catalysts; Water splitting; Large-size 


\section{Introduction}

Growing concerns regarding the energy crisis and environmental pollution prompts the exploration of sustainable energy sources as substitutes for traditional fossil fuels [1, 2]. As an environmentally friendly energy carrier, molecular hydrogen $\left(\mathrm{H}_{2}\right)$ plays a critical role in sustainable energy systems $[3,4]$. Among the technologies for $\mathrm{H}_{2}$ production, the electrocatalytic $\mathrm{H}_{2}$ evolution reaction (HER) from water splitting is the most effective and economical route because of its high energy-conversion efficiency and environmentally benign process [5-7]. It has been confirmed that precious platinum (Pt)-based materials play a leading role in current $\mathrm{H}_{2}$-production technology, such as water-alkali electrolysis $[8,9]$. However, the scarcity and high cost of Pt severely hamper its large-scale industrial applications. Therefore, it is crucial to explore inexpensive, alternative electrocatalysts that are made from earth-rich elements and have good activity and durability. Furthermore, water electrolysis should be carried out in either strongly acidic or alkaline electrolyte to minimize the overpotentials in the electrolyte [10]. Hence, development of a bifunctional catalyst that is based on earthrich elements and has high activity for both HER and oxygen evolution reaction (OER) in the same electrolyte is essential for simplifying the system and reducing manufacturing costs of $\mathrm{H}_{2}$.

In the past decades, a number of non-noble HER electrocatalysts based on transition metals and their compounds have been explored. Among the transition metals explored, $\mathrm{Ni}$ atoms possess an appropriate hydrogen surface adsorption energy, which makes them broadly recognized as excellent water dissociation centers [11, 12]. However, during the catalytic process on a $\mathrm{Ni}$ surface, the adsorption sites for $\mathrm{H}$ atoms may be occupied by $\mathrm{OH}^{-}$species. This causes a decrease in the active sites, which leads to a dramatic decline of catalytic activity. Ni foam (NF) is a low-cost and three-dimensional porous structure that is commonly used as the electrodes of alkaline electrolyzers for commercial applications [13]. Nanostructuring and surface engineering research has aimed to improve the catalytic performance of NF through maximizing the number of catalytic active sites and promoting mass transport. Different types of Nibased materials (including metallic Ni, Ni-based alloys, oxides, nitrides, phosphides, and sulfides) coated on NF have been intensively studied as HER and OER catalysts for water splitting [14-23]. Despite the largely improved catalytic performance, the process for large-scale preparation and application of these catalysts is less impressive and satisfactory. Moreover, the introduction of heteroatoms (e.g., N, S, P, and Se) is not beneficial for the recovery and recycling of the electrode. With increasing demands for $\mathrm{Ni}$ worldwide, increasing $\mathrm{Ni}$ recycling and reducing waste are tangible goals for making substantial strides toward sustainability [24].

Recently, some nanoscale metal and metal oxide (M/ $\mathrm{MO}_{\mathrm{x}}$ ) heterostructures have been fabricated and exhibit high HER catalytic activity and stability; this is probably because of the synergistic effects of $\mathrm{M}$ and $\mathrm{MO}_{\mathrm{x}}$, including $\mathrm{Ni} / \mathrm{NiO}$ heterostructures [25-33]. However, these porous $\mathrm{Ni} / \mathrm{NiO}$ composites are commonly powder and are fabricated through a complicated process, involving a sequence of hydrothermal, chemical reduction, and high-temperature processing [25, 26]. In addition, the preparation process of a traditional catalytic electrode that normally contains the addition of binder additives and carbon is also inconvenient. Hence, the search for economic, environmentally friendly, and feasible approaches to fabricate high-performance $\mathrm{Ni}$ based catalysts for large-scale water splitting is still pursued and highly challenging.

In this work, we engineer the surface of commercial NF by quickly coating a cluster of Ni nanodots (NiNDs) $(\sim 2 \mathrm{~nm})$ via electrochemical deposition. After drying in air, $\mathrm{NiO} /$ NiND composites can be obtained in a one-step procedure for constructing the binder-free and heteroatom-free $\mathrm{NiO} /$ NiNDs@NF electrodes. For comparison with commercial $\mathrm{NF}$, the catalytic activity and durability of the NiO/NiNDs@ NF electrodes toward HER and OER were greatly enhanced. The rough surface and porous structure of this composite with NiNDs can simultaneously expose more active sites with enhanced electrical conductivity. This NiO/NiND electrode consequently displays high activity and durability for electrocatalytic water splitting. The bifunctional catalytic electrode can enable highly efficient alkaline water electrolysis with $10 \mathrm{~mA} \mathrm{~cm}^{-2}$ at a cell voltage of only $1.70 \mathrm{~V}$. More practically, a large-sized $\left(S \sim 70 \mathrm{~cm}^{2}\right) \mathrm{NiO} / \mathrm{NiNDs} @$ NF electrode fabricated using this method has also been demonstrated. This large-sized electrocatalytic electrode can enable alkaline water electrolysis with $13 \mathrm{~mA} \mathrm{~cm}{ }^{-2}$ at $4.68 \mathrm{~V}$ (including electrical resistive loss in the electrolyte and electrode surfaces) [13] with superior durability. 
Importantly, these $\mathrm{NiO} / \mathrm{NiNDs}$ can be easily removed using diluted $\mathrm{HNO}_{3}$ aqueous solution for the recovery and recycling of $\mathrm{Ni}$ foam and hydrated $\mathrm{Ni}\left(\mathrm{NO}_{3}\right)_{2}$. This NiO/NiNDs@ $\mathrm{NF}$ electrode was prepared via one-step electrodeposition, which shortens the preparation process of the traditional electrode that normally contains added carbon and binder additives. With the low-cost, facile, and prompt fabrication strategy and the easy recycling property, this could be promising for water electrolysis devices used for large-scale $\mathrm{H}_{2}$ production.

\section{Experimental}

\subsection{Fabrication of Electrocatalytic Electrodes}

Commercial Ni foam (thickness: $0.5 \mathrm{~mm}$ ) was first cleaned with acetone and then soaked in $0.5 \mathrm{M} \mathrm{HNO}_{3}$ for $10 \mathrm{~min}$ to remove the $\mathrm{NiO}$ from the surface. It was then washed with water and dried at room temperature. Ni nanoparticles were electrodeposited on the $\mathrm{Ni}$ foam in a $\mathrm{N}_{2}$-saturated acetonitrile solution containing $0.1 \mathrm{M} \mathrm{Ni}\left(\mathrm{NO}_{3}\right)_{2} \cdot 6 \mathrm{H}_{2} \mathrm{O}$ (Residual water should first be eliminated through electrolysis.) ITO glass was used to electrodeposit and collect sample for $\mathrm{N}_{2}$ adsorption-desorption isothermal measurements. The electrochemical deposition process was conducted in a threeelectrode system at a potential of $-1.46 \mathrm{~V}$ (vs. RHE) using an electrochemical workstation (GAMRY-111000) with Ag/ $\mathrm{Ag}^{+}$as a reference electrode, $\mathrm{Pt}$ wire as a counter electrode, and $\mathrm{Ni}$ foam as the working electrode. The mass loading of active materials can be adjusted by controlling the deposition time. The NiNDs@NF electrode was then washed with acetonitrile and dried in air at room temperature for 10 min. The NiO/NiNDs@NF electrode was prepared via oxidization of the pre-electrodeposited NiNDs in the air after drying. The prepared electrode can be directly used to collect the polarization curves or stored under vacuum for future use. The 120-s deposited electrode (loading of $\mathrm{NiO} /$ NiNDs was determined from the difference of the weight of NF before and after electrodeposition and was found to be $\sim 1 \mathrm{mg} \mathrm{cm}^{-2}$ ) was used for the material characterizations and electrochemical tests. The large-sized NiO/NiNDs@NF electrode was fabricated using the same procedure with a large-sized carbon plate as the counter electrode. To prepare the Pt/C@NF electrodes, $1 \mathrm{mg}$ of $20 \mathrm{wt} \% \mathrm{Pt} / \mathrm{C}$ or $\mathrm{RuO}_{2}$ (99.9\%) was mixed with $90 \mu \mathrm{L}$ of water, $50 \mu \mathrm{L}$ of ethanol, and $10 \mu \mathrm{L}$ of $5 \mathrm{wt} \%$ Nafion solution. The mixture was sonicated for $1 \mathrm{~h}$ to form a homogeneous ink. Then, $25 \mu \mathrm{L}$ of the suspension was drop dried onto $\mathrm{NF}\left(0.5 \mathrm{~cm}^{2}\right.$ loading of $1 \mathrm{mg} \mathrm{cm}^{-2}$ for the active mass).

\subsection{Materials Characterizations}

The morphologies and structures of the $\mathrm{NiO} / \mathrm{NiND}$ composites were investigated using scanning electron microscopy (SEM, LEO 1530) with an energy-dispersive X-ray (EDX) attachment (Zeiss) and using high-resolution transmission electron microscopy (HRTEM, JEOL JEM-2100). X-ray photoelectron spectroscopy (XPS, Thermo Scientific, Escalab 250Xi) was employed to analyze the composition of the $\mathrm{NiO} / \mathrm{NiND}$ composites. $\mathrm{N}_{2}$ adsorption/desorption isotherms were obtained using a Quantachrome Autosorb-1 system at $77 \mathrm{~K}$.

\subsection{Electrochemical Measurements}

Cyclic voltammetry (CV) for HER and OER catalytic activity measurements was performed using a standard threeelectrode system controlled by a GAMRY 11100 electrochemistry workstation. The current densities were calculated based on the projected geometric area of an electrode. All of the electrolytes were saturated by $\mathrm{N}_{2}$ bubbles for $30 \mathrm{~min}$ before the experiments. Different catalyst electrodes were used as the working electrode, a graphite plate was used as the counter electrode, and $\mathrm{Ag} / \mathrm{AgCl}$ was used as the reference electrode. The reference was calibrated against and converted to the reversible hydrogen electrode (RHE; $E$ $(\mathrm{RHE})=E(\mathrm{Ag} / \mathrm{AgCl})+1.024 \mathrm{~V} ; \mathrm{pH}=14)$. Water electrolysis measurements were carried out in a standard two-electrode system using the same deposited catalyst electrodes as the cathode and anode. Linear sweep voltammetry was carried out at $2 \mathrm{mV} \mathrm{s}^{-1}$ for the polarization curves. Chronopotentiometry was measured under a constant current density of $13 \mathrm{~mA} \mathrm{~cm}^{-2}$. All of the polarization curves in the three-electrode system were $i R$-corrected. Before measurements were made, a resistance test was conducted and $i R$ compensation was applied using the GAMRY software. $R$ is the equivalent series resistance, which was determined from electrochemical impedance spectroscopy (EIS). All of the data for the two-electrode electrolyzer were recorded without $i R$ compensation. The faradaic efficiency was calculated 


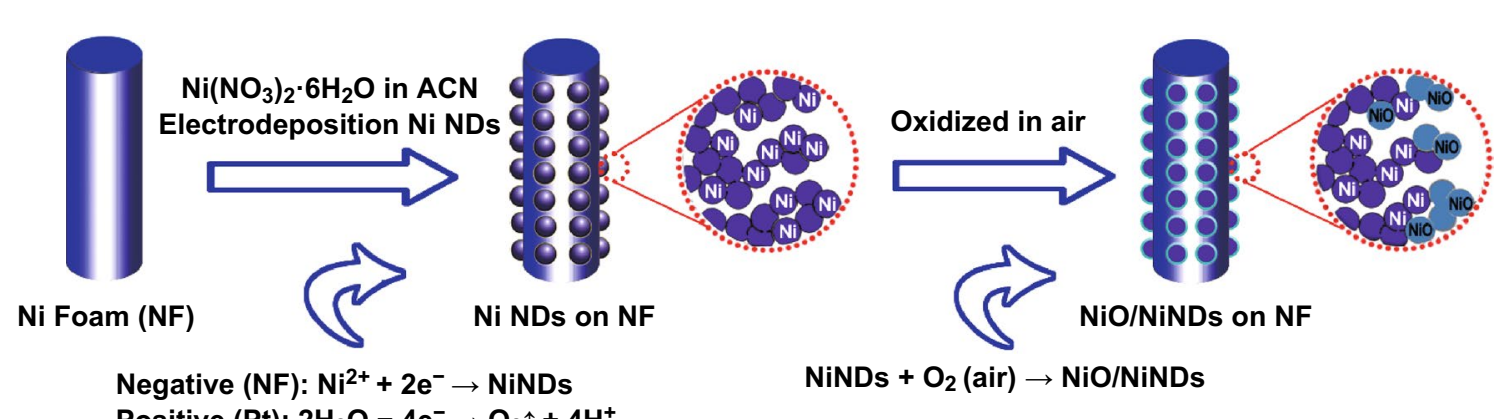

Scheme 1 Schematic illustration of the fabrication process of NiO/NiND composites on nickel foam and the corresponding reaction during and after electrodeposition

by comparing the amount of gas determined from theoretical calculations and that determined from experimental measurements. $\mathrm{H}_{2}$ and $\mathrm{O}_{2}$ were collected using a water-drainage method, and the amounts of each were calculated using the moles of $\mathrm{H}_{2}$ and $\mathrm{O}_{2}$ generated from the overall water splitting with the ideal gas law. The theoretical amounts of $\mathrm{H}_{2}$ and $\mathrm{O}_{2}$ were calculated using $I-t$ curve and by applying Faraday's law [17]. The content of active materials was obtained by comparing the weight of the electrode before and after electrodeposition. EIS measurements were carried out by applying an $\mathrm{AC}$ voltage with $5 \mathrm{mV}$ amplitude in a frequency range from 0.01 to $100 \mathrm{kHz}$ at an overpotential of $0 \mathrm{~V}$ in $1.0 \mathrm{M} \mathrm{KOH}$.

\section{Results and Discussion}

\subsection{Fabrication of NiO/NiNDs Composites on NF}

The fabrication process of $\mathrm{NiO} / \mathrm{NiND}$ composites is illustrated in Scheme 1. First, NiND clusters were deposited on $\mathrm{NF}$ via an electrochemical reduction process of $\mathrm{Ni}^{2+} \rightarrow \mathrm{Ni}^{0}$ in $\mathrm{N}_{2}$-saturated acetonitrile (ACN) solution (Fig. S1 and Movie S1). The corresponding reactions are also shown in Scheme 1 , in which $\mathrm{Ni}^{2+}$ was reduced to $\mathrm{Ni}^{0}$ on the negative electrode instead of the $\mathrm{H}_{2}$ evolution reaction occurring in aqueous solution at the same potential (Fig. S2). This is because of the wider potential window of ACN (Fig. S3). Moreover, the black film composed of NiNDs was accessible only in ACN instead of other common organic solvents (e.g., DMSO, THF, DMF, and ethanol) that have a similar wide potential window. This is probably because of the higher thermodynamic stability of $\left[\mathrm{Ni}(\mathrm{ACN})_{6}\right]^{2+}[34]$. It has also been reported that the higher donor property of $\mathrm{ACN}$ prevents the directional growth of nucleation for the formation of a compact metallic film. The same effect of ACN has also been observed during electrodeposition of $\mathrm{Co}$ or $\mathrm{Fe}$ nanoparticles using the ACN solution [35, 36]. Meanwhile, these deposited nanoparticles all showed high reducibility (Fig. S4), providing a convenient and quick method for fabricating nanoscale $\mathrm{NiO} / \mathrm{Ni}$ composites. Consequently, the NiO/NiNDs@NF electrode can be obtained instantly when these electrodeposited electrodes were exposed to air. This strategy, which does not include adding carbon and binder additives, greatly shortens the preparation process of the traditional electrode.

\subsection{Materials Characterization}

The morphologies and structures of the NiO/NiND composites were first examined using SEM and TEM. A representative SEM image of the $\mathrm{NiO} / \mathrm{NiND}$ composites is shown in Fig. 1a. Integrated spherical nodules formed by NiND clusters with different sizes were observed on the NF. The whole deposition process is described in Figs. S5, S6. With an increase in the deposition time, the thickness of the film increased gradually and finally became more easily detached from NF (Fig. S5). Therefore, the 120-s deposited materials were used for characterization and fabrication of the electrocatalytic electrodes. The growth process of NiND clusters can be observed from the low-scale SEM images (Fig. S6). At the beginning of the deposition process, plenty of NiND clusters formed uniformly on the surface of $\mathrm{NF}$, and then, these clusters grew, accumulated, and integrated with each other. The homogeneous spatial distributions of $\mathrm{Ni}$ and $\mathrm{O}$ in the composites are clearly verified by the corresponding energy-dispersive spectroscopy (EDS) 

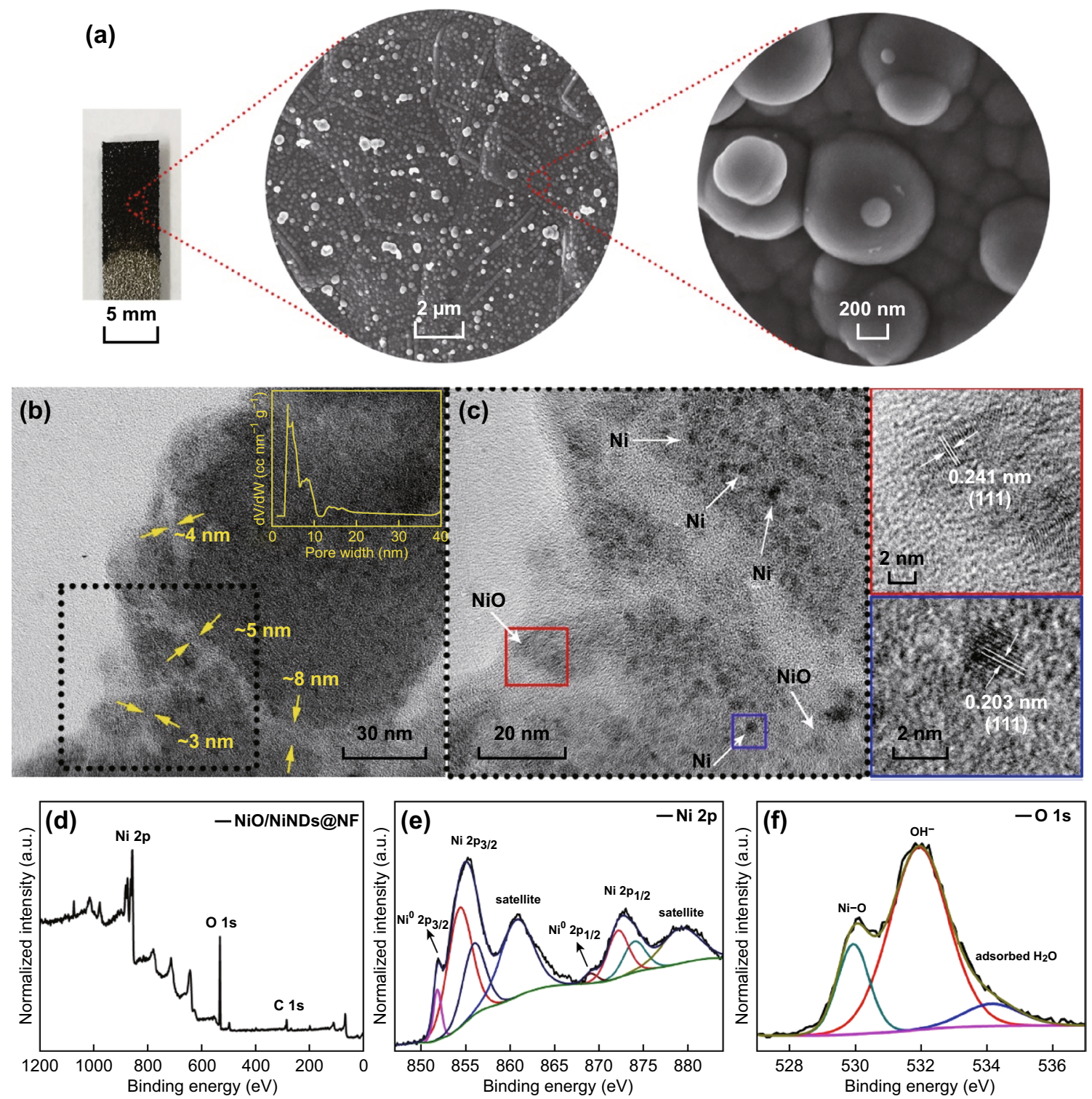

Fig. 1 Structure and components of NiO/NiND composites after $120 \mathrm{~s}$ of deposition. a Photographic images of the NiO/NiNDs@NF electrode, SEM image, and the corresponding magnified SEM image. b TEM and c HRTEM images (the magnified view of the NiO and Ni crystal lattice is in the red and blue frame respectively); inset of $\mathrm{b}$ is the corresponding BJH pore size distribution curve shown by the yellow line; $\mathbf{d}-\mathbf{f}$ full XPS spectrum, and XPS spectra of Ni $2 p$ and $\mathrm{O} 1 s$. (Color figure online)

mapping images, and the atomic ratio of $\mathrm{Ni} / \mathrm{O}$ approached 3:1 (Fig. S7). The structure of the NiO/NiND composites was further investigated using high-resolution transmission electron microscopy (HRTEM) measurements, which are shown in Fig. 1b, c. Figure 1b shows the porous structures among the nanoparticles, and it is observed that the hollow space is between $3 \sim 8 \mathrm{~nm}$. The hollow space is beneficial for the penetration and diffusion of electrolytes. Meanwhile, the specific surface area and pore size distribution of the
$\mathrm{NiO} / \mathrm{NiND}$ composites were examined using $\mathrm{N}_{2}$ adsorption-desorption isothermal measurements. The NiO/NiND sample shows an apparent hysteresis loop in the sorption isotherm, indicating its mesoporous structure (Fig. S8). The pore size distribution curve was obtained using the Barrett-Joyner-Halenda (BJH) method, and the results show a narrow range of mesopores between $3 \sim 10 \mathrm{~nm}$ and a broad peak centered at $15 \mathrm{~nm}$ (inset of Fig. 1b). From calculations, the Brunauer-Emmett-Teller (BET) surface area of the NiO/ 

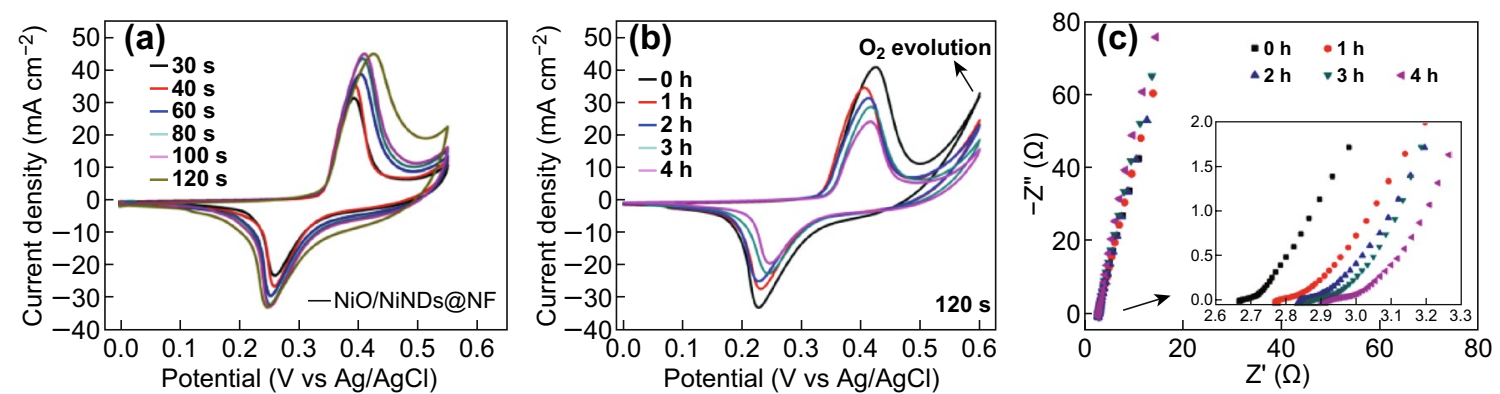

Fig. $2 \mathrm{CV}$ characteristics (scan rate of $5 \mathrm{mV} \mathrm{s}^{-1}$ ) of a NiO/NiNDs@ NF electrodes with different deposition time and b 120-s deposited NiO/ NiNDs@NF electrodes before and after heating at $200{ }^{\circ} \mathrm{C}$. c Corresponding Nyquist plots of the curves shown in panel b over the frequency range of $0.01 \mathrm{~Hz}-100 \mathrm{kHz}$ with $5 \mathrm{mV}$ AC amplitude at an overpotential of $0 \mathrm{~V}$ in $1.0 \mathrm{M} \mathrm{KOH}$. Inset is a local enlargement of the high-frequency region

NiND composite is $69 \mathrm{~m}^{2} \mathrm{~g}^{-1}$. HRTEM images in Fig. 1c further demonstrate that the spherical nodules are composed of nanoparticles that are $2 \mathrm{~nm}$ in size. The interplanar spacing of $0.203 \mathrm{~nm}$ matches well with the $d_{111}$ spacing of metal $\mathrm{Ni}$ (JCPDS No. 65-2865), and another lattice fringe spacing of $0.241 \mathrm{~nm}$ corresponds to the (111) plane of $\mathrm{NiO}$ (JCPDS No. 47-1049). These observations indicate that the obtained composites consist of both metallic $\mathrm{NiO}$ and $\mathrm{Ni}$ nanoparticles, providing a favorable low resistance pathway for electron transfer. To further confirm the NiO/NiND composites, XPS analyses were conducted. Figure 1d displays the full spectrum of the $\mathrm{NiO} / \mathrm{NiND}$ composite, in which the atomic ratio of $\mathrm{Ni} / \mathrm{O}$ is approximately $3: 1$. The high-resolution XPS spectra in the Ni $2 p$ and $\mathrm{O} 1 s$ regions are presented in Fig. 1e, f. The peaks centered at 854.4 and $856.2 \mathrm{eV}$ correspond to $\mathrm{Ni}$ (II) $2 p_{3 / 2}$, and peaks at 872.1 and $873.9 \mathrm{eV}$ originate from $\mathrm{Ni}$ (II) $2 p_{1 / 2}$ [37, 38]. The characteristic peaks of $\mathrm{Ni}^{0}$ are located at 852.4 and $869.6 \mathrm{eV}$, respectively, for $\mathrm{Ni}$ $2 p_{3 / 2}$ and $\mathrm{Ni} 2 p_{1 / 2}$ [39]. Satellite peaks of Ni $2 p_{3 / 2}$ and $2 p_{1 / 2}$ are observed at 860.7 and $879.3 \mathrm{eV}$. In addition to the peaks of $\mathrm{Ni}^{2+}$, the noticeable characteristic peaks of $\mathrm{Ni}^{0}$ are also observed, indicating the existence of metal $\mathrm{Ni}$. The $\mathrm{O} 1 \mathrm{~s}$ signal shows three peaks located at 530,532, and $534 \mathrm{eV}$, which can be assigned to $\mathrm{O}^{2-}$ in $\mathrm{NiO}$, hydroxyl groups $\left(\mathrm{OH}^{-}\right)$, and surface-adsorbed $\mathrm{H}_{2} \mathrm{O}$, respectively. These observations are in accord with the results of reported $\mathrm{NiO} / \mathrm{Ni}$ composites $[26,27]$. Moreover, a lot of carbon-containing functional groups are observed in the high-resolution XPS spectrum of C $1 s$ (Fig. S9). These groups should come from coordinating ACN molecules or their derivatives because of the high thermodynamic stability of $\left[\mathrm{Ni}(\mathrm{ACN})_{6}\right]^{2+}$. During the reduction process of $\mathrm{Ni}^{2+}$ to $\mathrm{Ni}$ in the electrodeposition of
NiNDs, some of the ACN molecules or derived groups are retained, and this probably leads to the formation of NiNDs. Similar results have been reported in the previous work for the electrodeposition of cobalt and iron nanoparticles using the ACN solution $[35,36]$.

\subsection{Electrochemical Properties of NiO/NiNDs@NF}

To investigate the electrochemical kinetics of the $\mathrm{NiO} /$ NiNDs@NF electrode, a three-electrode system with $1 \mathrm{M}$ $\mathrm{KOH}$ as an aqueous electrolyte was used to measure the electrochemical performances of the NiO/NiNDs@NF electrodes. The CV curves of the NiO/NiNDs@NF electrode with different deposition times are displayed in Fig. 2a. Each $\mathrm{CV}$ curve has the same pair of distinct redox peaks in the potential range of $0-0.55 \mathrm{~V}$ at a scan rate of $5 \mathrm{mV} \mathrm{s}^{-1}$, indicating the faradaic redox reaction [40]:

$\mathrm{NiO}+\mathrm{OH}^{-} \rightleftharpoons \mathrm{NiOOH}+\mathrm{e}^{-1}$

The corresponding right shift of the anodic potentials may result from the increased conductivity that occurs with an increase in the internal metallic $\mathrm{Ni}$ content of the $\mathrm{NiO} / \mathrm{NiND}$ composite, which results in decreased polarization loss [41, 42]. By re-plotting peak current versus scan rate, both the anodic and cathodic plots show a linear relationship regardless of scan rate (Fig. S10), suggesting a controlled semiinfinite diffusion process during cycling. To investigate the effects of NiNDs on the electrochemical performance of NiO/NiND composites, the NiO/NiNDs@NF electrodes were heated at $200{ }^{\circ} \mathrm{C}$ in air to aggravate the oxidation of NiNDs. Figure 2b shows the CV curves of the NiO/NiNDs@ $\mathrm{NF}$ electrodes with different heating times. The redox peaks for the NiO/NiNDs@NF electrode without heating treatment show a larger peak area and higher anodic potential. With an 

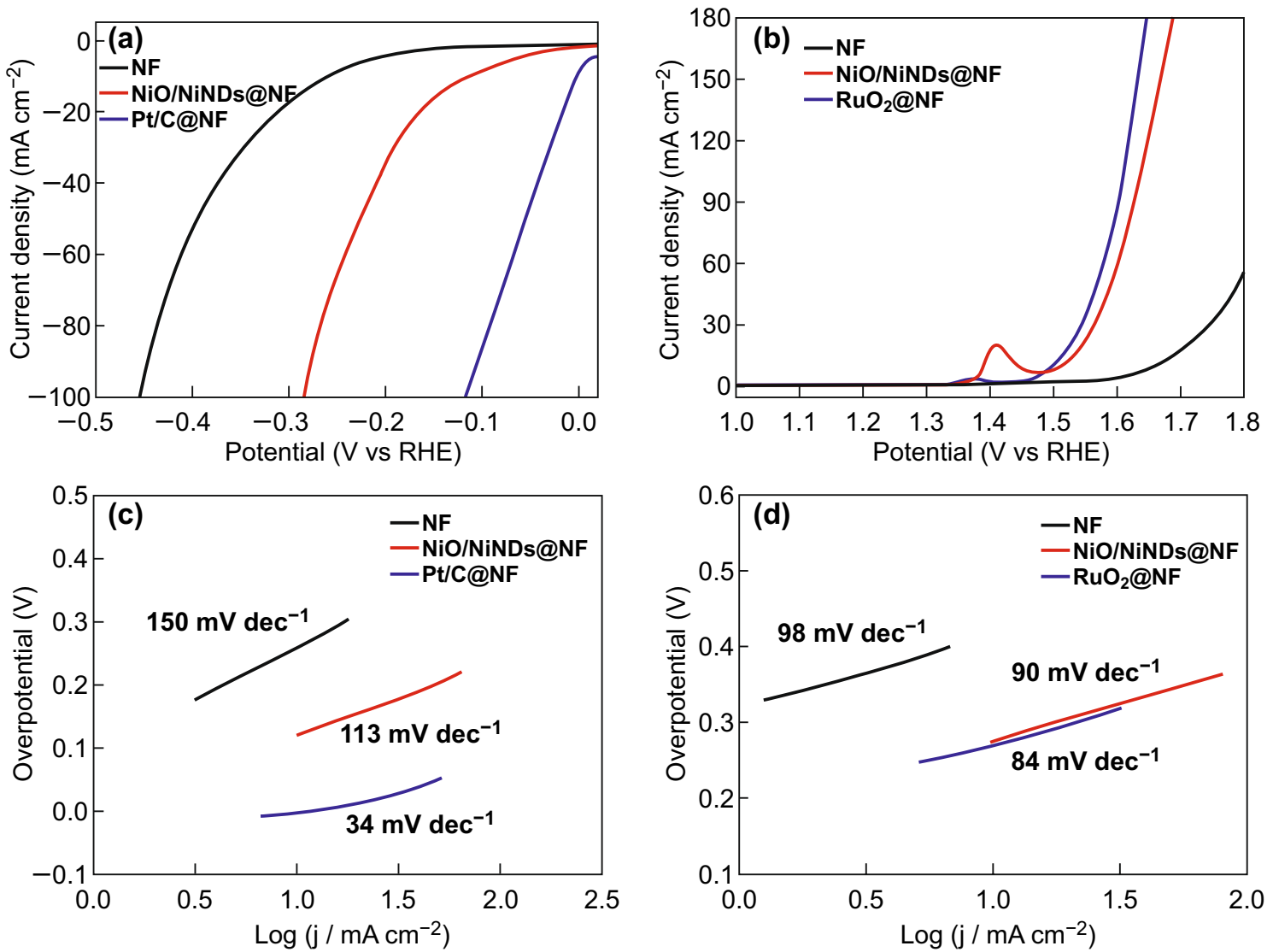

Fig. 3 a HER and b OER characteristics of different catalyst electrodes under $1 \mathrm{mg} \mathrm{cm}^{-2}$ loading determined using linear sweep voltammetry with a three-electrode configuration in $1 \mathrm{M} \mathrm{KOH}$ aqueous electrolyte. All of the scan rates were $2 \mathrm{mV} \mathrm{s}^{-1}$. Tafel plots of different catalyst electrodes for $\mathbf{c}$ HER and $\mathbf{d}$ OER

increase in the heating time, the stable redox peaks accordingly become smaller, and meanwhile the catalytic current for OER also gradually weakens. This may result from the decreased conductivity that occurs because of the decrease in metal Ni content. The corresponding EIS spectra of the treated NiO/NiNDs@NF electrodes are shown in Fig. 2c. The near-vertical slopes of the Nyquist plots in the lowfrequency region reveal that the electrodes display a capacitive-like behavior. This behavior indicates the fast diffusion of the electrolyte (inset of Fig. 2c) [43]. The charge transfer resistance $\left(R_{\mathrm{ct}}\right)$ obtained from the simulated diameter of the resistor-capacitor loop increases with the decrease in Ni content, which is in accord with the increase of $R_{\mathrm{s}}$ and decrease in electrical conductivity for the $\mathrm{NiO} / \mathrm{NiND}$ composites (Fig. S11). These results further reveal that the metallic NiNDs are responsible for the high conductivity of the NiO/NiND composites, which endows the NiO/NiNDs@ $\mathrm{NF}$ electrode with a higher electrochemical performance to enhance its catalytic properties.

\subsection{Catalytic Activity of NiO/NiNDs@NF}

Catalytic activity of electrodes toward HER and OER was evaluated using linear sweep voltammetry (LSV) with a three-electrode system in $1.0 \mathrm{M} \mathrm{KOH}$ and with a scan rate of $2 \mathrm{mV} \mathrm{s}^{-1}$. For comparison, the catalytic activity toward HER of bare NF, the commercial $20 \mathrm{wt} \% \mathrm{Pt} / \mathrm{C}$, and $\mathrm{RuO}_{2}$ deposited on NF with the same loading (weight density of $1 \mathrm{mg} \mathrm{cm}^{-2}$ ) were also tested. As-measured reaction currents do not directly reflect the intrinsic behavior of catalysts because of the effect of ohmic resistance, and thus, an $i R$ correction was applied to all of the initial data for further analysis. As seen in Fig. 3a, the electrocatalytic performance of NiO/NiNDs@NF is much better than that of NF. To achieve a current density of $10 \mathrm{~mA} \mathrm{~cm} \mathrm{~cm}^{-2}$, the NiO/NiNDs@ $\mathrm{NF}$ electrode requires an overpotential $\left(\eta_{\mathrm{HER}}\right)$ of $119 \mathrm{mV}$, which is $119 \mathrm{mV}$ higher than that of the Pt/C@NF electrode $(0 \mathrm{mV})$. This overpotential is smaller than the behavior 

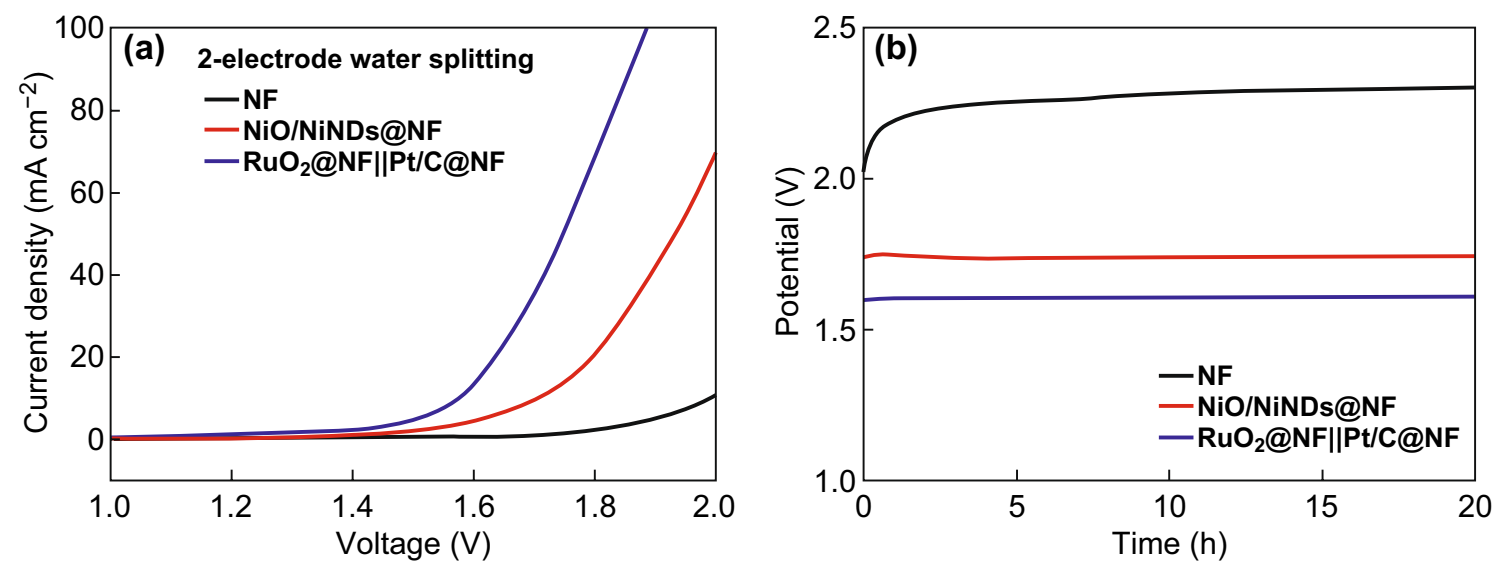

Fig. 4 a Overall water-splitting characteristics of different catalyst electrodes in a two-electrode configuration. b Chronopotentiometric curves of water electrolysis for different catalyst electrodes in a two-electrode configuration with a constant current density of $13 \mathrm{~mA} \mathrm{~cm}^{-2}$ (without $i R$ correction)

of other reported Ni- and Co-based HER electrocatalysts when operated in alkaline aqueous solution. Such catalysts include the $\mathrm{Ni}$ inverse opal $(240 \mathrm{mV})$ [44], $\mathrm{Ni}_{2} \mathrm{P}$ nanoparticles $(180 \mathrm{mV})$ [45], $\mathrm{Ni}_{3} \mathrm{~S}_{2} /$ carbon nanotube composites (350 mV) [46], $\mathrm{Ni}_{\mathrm{x}} \mathrm{Co}_{10-\mathrm{x}} / \mathrm{C}$ nanoflakes (370 mV) [47], and $3 \mathrm{DOM} / \mathrm{m} \mathrm{Ni}(171 \mathrm{mV})$ [48]. Meanwhile, the overpotential $(164 \mathrm{mV})$ for $20 \mathrm{~mA} \mathrm{~cm}^{-2}$ is also smaller or comparable to that of other modified NF (Table S1) and reported Ni- and Co-based bifunctional catalysts, including $\mathrm{Ni}_{2} \mathrm{P}(255 \mathrm{mV})$ [49], $\mathrm{NiCo}_{2} \mathrm{~S}_{4} /$ carbon cloth (190 mV) [50], and $\mathrm{Ni}_{5} \mathrm{P}_{4} / \mathrm{Ni}$ foil $(169 \mathrm{mV})$ [51]. Figure $3 \mathrm{c}$ shows the Tafel plots of the bare NF, NiO/NiNDs@NF, and Pt/C@NF. The Tafel slopes of 150,113 , and $34 \mathrm{mV} \mathrm{dec}{ }^{-1}$ for NF, NiO/NiNDs@NF, and $\mathrm{Pt} / \mathrm{C} @ \mathrm{NF}$, respectively, were determined from the fitting of the linear region of the corresponding Tafel plots using the Tafel equation $(\eta=b \log j+a$, where $j$ is the current density and $b$ is the Tafel slope). The relatively small Tafel slope of NiO/NiNDs@NF indicates a faster increase in the HER rate with an increase in potential.

The OER characteristics of these different electrodes are shown in Fig. 3b. The NiO/NiNDs@NF electrode also exhibits excellent catalytic activity toward OER. In the three-electrode configuration, the NiO/NiNDs@NF electrode has a much higher current density than the bare NF and an onset potential as low as $1.55 \mathrm{~V}$ versus RHE. It requires an overpotential $\left(\eta_{\mathrm{OER}}\right)$ of $360 \mathrm{mV}$ to reach a (projected geometric area) current density of $50 \mathrm{~mA} \mathrm{~cm}{ }^{-2}$, which is $21 \mathrm{mV}$ more than that of the $\mathrm{RuO}_{2} @ \mathrm{NF}$ electrode. Meanwhile, this overpotential is comparable to the behavior of other modified NF (Table S1) and reported state-of-the-art Ni- and
Co-based bifunctional catalysts, such as $\mathrm{Ni}-\mathrm{P} / \mathrm{Cu}$ foam (410 mV) [52], $\mathrm{Ni}_{3} \mathrm{Se}_{2} / \mathrm{Cu}$ foam (343 mV) [53], $\mathrm{Ni}_{5} \mathrm{P}_{4} / \mathrm{Ni}$ foil (363 mV) [51], and CoSe/Ti mesh (341 mV) [54]. The anodic peak at $1.41 \mathrm{~V}$ corresponds to the oxidation of $\mathrm{NiO}$. Moreover, a minor anodic peak is observed at $1.35 \mathrm{~V}$ in the magnified LSV curve, which corresponds to the oxidation of NiNDs (Fig. S12). The Tafel slope for the NiO/NiNDs@ NF electrode is calculated to be $90 \mathrm{mV} \mathrm{dec}^{-1}$, which is close to the corresponding value of the $\mathrm{RuO}_{2} @ \mathrm{NF}\left(84 \mathrm{mV} \mathrm{dec}{ }^{-1}\right)$ electrode and smaller than the corresponding value of bare $\mathrm{NF}\left(98 \mathrm{mV} \mathrm{dec}^{-1}\right)$ (Fig. 3d). Moreover, to further investigate the effects of NiNDs, we used LSV and the heat-treated NiO/NiNDs@NF as the electrode to test its electrocatalytic properties for HER and OER. Obviously, the heating treatment (at $200{ }^{\circ} \mathrm{C}$ in air) has large effects on HER and OER performance, which gradually declined with an increase in the heating time (Fig. S13). These results further indicate that the NiNDs play an important role in the excellent electrocatalytic activity toward HER and OER.

To test the applicability as a bifunctional electrocatalyst for overall water electrolysis, an electrolyzer that used a NiO/NiNDs@NF electrode in 1.0 M KOH as both the anode and cathode was assembled (NiO/NiNDs@ $\mathrm{NF} \| \mathrm{NiO} /$ NiNDs@NF). As a control, another water electrolyzer $\mathrm{NF} \| \mathrm{NF}$ and $\mathrm{RuO}_{2} @ \mathrm{NF} \| \mathrm{Pt} / \mathrm{C} @ \mathrm{NF}$ are also made. Figure 4a shows the polarization curves of the different electrolyzers. Overall, NiO/NiNDs@NF/NiO/NiNDs@NF can achieve $10 \mathrm{~mA} \mathrm{~cm}{ }^{-2}$ water-splitting current by applying just $1.7 \mathrm{~V}$ across the electrodes, which is a much better performance than that of bare NF. This potential is only $124 \mathrm{mV}$ more 
than that of $\mathrm{RuO}_{2} @ \mathrm{NF} \| \mathrm{Pt} / \mathrm{C} @ \mathrm{NF}$. Although this value is larger than that of $\mathrm{RuO}_{2} @ \mathrm{NF} \| \mathrm{Pt} / \mathrm{C} @ \mathrm{NF}$, it is comparable to the values required by electrolyzers that are based on the other reported state-of-the-art $\mathrm{Ni}$ - and Co-based bifunctional catalysts, such as $\mathrm{Ni}_{3} \mathrm{~S}_{2} / \mathrm{Ni}$ foam $\| \mathrm{Ni}_{3} \mathrm{~S}_{2} / \mathrm{Ni}$ foam (above $1.7 \mathrm{~V}$ ) [55], $\mathrm{NiFe} \mathrm{LDH} / \mathrm{Ni}$ foam $\| \mathrm{NiFe} \mathrm{LDH} / \mathrm{Ni}$ foam (1.7 V) [56], $\mathrm{Ni}_{5} \mathrm{P}_{4} / \mathrm{Ni}$ foil $\| \mathrm{Ni}_{5} \mathrm{P}_{4} / \mathrm{Ni}$ foil (1.68 V) [51], $\mathrm{NiCo}_{2} \mathrm{~S}_{4} /$ carbon cloth $\| \mathrm{NiCo}_{2} \mathrm{~S}_{4} /$ carbon cloth (1.68 V) [50], and NiS/ $\mathrm{Ni}$ foam $\| \mathrm{NiS} / \mathrm{Ni}$ foam (above $1.64 \mathrm{~V}$ ) [57]. All of the above results demonstrate the exciting potential of this Ni-based electrode for water electrolysis.

\subsection{Catalytic Stability of NiO/NiNDs@NF}

Long-term electrocatalytic stability is another important criterion for water-splitting electrocatalysts because a longer lifetime of a device reduces the cost of the resulting $\mathrm{H}_{2}$. To assess the durability of the NiO/NiNDs@NF electrodes, an applied current density was set at $13 \mathrm{~mA} \mathrm{~cm}^{-2}$. A constant potential of $1.74 \mathrm{~V}$ can be well maintained for at least $20 \mathrm{~h}$ without any decay (Fig. 4b), and this indicates the high stability of the NiO/NiNDs@NF electrode. For comparison, the applied potential of $\mathrm{RuO}_{2} @ \mathrm{NF} \| \mathrm{Pt} / \mathrm{C} @$ $\mathrm{NF}(1.61 \mathrm{~V})$ is nearly $120 \mathrm{mV}$ less than that of the $\mathrm{NiO} /$ NiNDs@NF electrode, and the NF (2.0 V) electrodes show a poor electrocatalytic activity and stability. The potential of the NF electrode increased greatly during the first few hours, suggesting a dramatic decline in the catalytic activity. Meanwhile, the faradaic efficiency during the overall water splitting is almost $100 \%$ for both HER and OER, and the molar ratio of $\mathrm{H}_{2}$ to $\mathrm{O}_{2}$ remains at 2:1 (Fig. S14). After the durability assessments, the NiO/NiNDs@NF electrodes were also tested using SEM and TEM, and the results indicate no topographic changes. This highlights the superior structural robustness of the NiO/NiND composites during the electrocatalytic HER and OER processes (Fig. S15). However, the NiNDs content decreased obviously after the long-term OER durability test (Fig. S16). The survival of some of the NiNDs is probably because of the existence of carbon-containing groups on the surface of NiNDs, which may retard the oxidation of NiNDs. It is worth mentioning that the excellent catalytic stability of $\mathrm{NiO} / \mathrm{NiND}$ composites should be attributed to the NiND survival in the electrochemical tests (Fig. S17).

\subsection{Proposed Mechanism of Electrocatalytic Property of $\mathrm{NiO} / \mathrm{Ni}$ composites}

On the basis of these results, we propose three explanations for the superior electrocatalytic performance of $\mathrm{NiO} / \mathrm{Ni}$ composites: First, the presence of metallic Ni nanoparticles increases the conductivity of the catalyst; this is beneficial for electron transport through $\mathrm{NiO}$ and improves the catalytic stability. Second, the rough surface and porous nanostructure enhance electron transfer by increasing the reaction area and preventing bubbles from growing; in turn, this increases the rate of electrolysis. Third, the synergistic effect of surface $\mathrm{NiO}$ and $\mathrm{Ni}$ nanoparticles can further improve the catalytic activity of $\mathrm{NiO} / \mathrm{Ni}$ composites. On the one hand, Ni supplies the active catalytic sites and highly improves the conductivity of the catalyst. On the other hand, the $\mathrm{OH}^{-}$that is generated by $\mathrm{H}_{2} \mathrm{O}$ splitting can preferentially attach to a $\mathrm{NiO}$ site at the interface because of strong electrostatic affinity to the locally positively charged $\mathrm{Ni}^{2+}$ species and the larger number of unfilled $d$ orbitals in $\mathrm{Ni}^{2+}$ than in $\mathrm{Ni}$ metal [25].

\subsection{Fabrication of Large-sized NiO/NiNDs@NF Electrode}

For further practical application, overall water splitting was also investigated in a large-sized catalytic electrode. As described in Fig. 5, NF that was $80 \mathrm{~cm}^{2}$ was used to fabricate the NiO/NiNDs@NF electrode via this method (Fig. 5a). Electrodeposition of NiNDs was conducted in the same way as described above, using a large-sized carbon plate as the counter electrode (Fig. 5b). During the electrodeposition process, formation of a black and uniform film was observed on the surface of NF. After electrodepositing and drying in air, a large-sized NiO/NiNDs@NF electrode with a $70 \mathrm{~cm}^{2}$ active area was obtained (Fig. 5c). The same surface topography (of integrated spherical nodules as small-sized electrodes) described above is seen in the SEM images (inset of Fig. 5c). As expected, the large-sized $\mathrm{NiO} /$ NiNDs@NF electrodes were directly used to electrocatalyze water decomposition in $1 \mathrm{M} \mathrm{KOH} \mathrm{(Fig.} \mathrm{5d} \mathrm{and} \mathrm{Movie}$ S2). All of these results demonstrate the feasibility of this method for large-scale production and practical applications in a water electrolyzer. In contrast to the previous smallsized electrodes $\left(S_{\text {electrode }} \sim 0.5 \mathrm{~cm}^{2}\right)$, this large-sized $\mathrm{NiO} /$ 

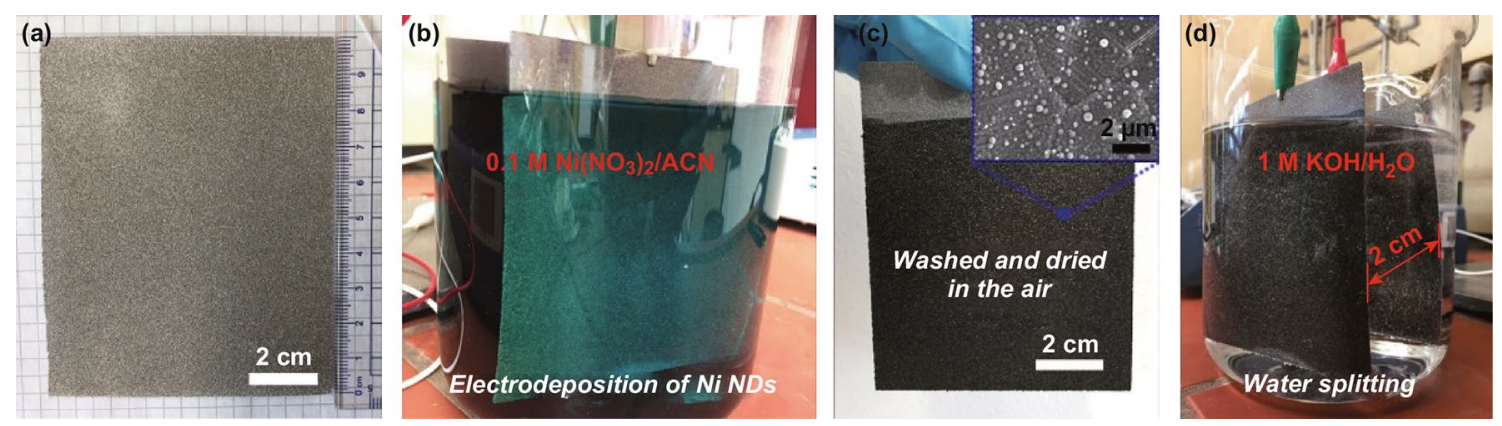

Fig. 5 Photographs of the preparation and application process of large-area NiO/NiNDs@NF electrodes: a Ni foam that is $80 \mathrm{~cm}^{2} . \mathbf{b}$ Electrodeposition process of NiNDs on NF. c The obtained NiO/NiNDs@NF electrode that has an effective geometric surface area of $70 \mathrm{~cm}^{2}$ (inset is an SEM image). d Generation of $\mathrm{H}_{2}$ and $\mathrm{O}_{2}$ bubbles on the NiO/NiNDs@NF electrode with a constant current density of $13 \mathrm{~mA} \mathrm{~cm}^{-2}$ (see SI for a video)

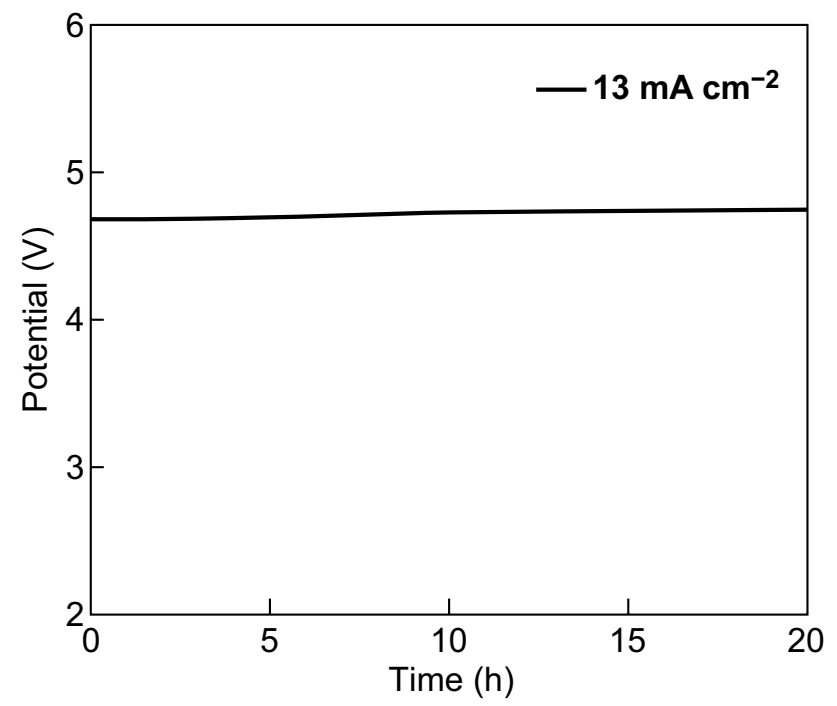

Fig. 6 Chronopotentiometric curve of water electrolysis using largesized NiO/NiNDs@NF\|NiO/NiNDs@NF $\left(S \sim 70 \mathrm{~cm}^{2}\right)$ with a constant current density of $13 \mathrm{~mA} \mathrm{~cm}^{-2}$

NiNDs@NF electrodes enable an alkaline water electrolyzer with $13 \mathrm{~mA} \mathrm{~cm}^{-2}$ at $4.68 \mathrm{~V}$ (without $i R$ correction). This illustrates the high applied potential for large-scale water electrolysis. The high potential drop mainly results from the larger additional resistance (including resistance losses in the electrolyte, substrate, and contact interface) [13]. More detailed work to decrease the resistance loss is under way.

The large-sized water electrolyzer also exhibited superior durability (Fig. 6). The excellent stability and fast preparation process greatly simplified the manufacturing procedures and saved time, which is advantageous for practical applications.

\subsection{Recycling $\mathrm{NF}$ and $\mathrm{Ni}\left(\mathrm{NO}_{3}\right)_{2}$}

These NiO/NiND composites can quickly dissolve in acid solution to form the corresponding salt of $\mathrm{Ni}^{2+}$, leading to the regeneration of NF. As seen in Fig. S18a, the color of the NiO/NiNDs@NF electrode changes gradually from black to silver-white when it is immersed in $0.5 \mathrm{M} \mathrm{HNO}_{3}$ solution. The SEM images further indicate that the spherical nodules on the surface of NF can be completely dissolved in $0.5 \mathrm{M}$ $\mathrm{HNO}_{3}$ solution for $20 \mathrm{~min}$ (Fig. S18b). In addition, the corrosion behavior of pure $\mathrm{NF}$ in $0.5 \mathrm{M} \mathrm{HNO}_{3}$ solution has been investigated. No vigorous reaction was observed, and there was a merely $4 \%$ decrease in the weight of NF after 20 min of the immersion treatment (Fig. S18c). This dissolution process of NF in NiO/NiNDs@NF should be slow because of the surface coating of NiO/NiNDs. Meanwhile, the dissolved product of NF and the concentrated treatment solution can also be used as a source of $\mathrm{Ni}\left(\mathrm{NO}_{3}\right)_{2}$. Thus, the regenerated $\mathrm{Ni}$ foam can be recycled and used in the fabrication of the NiO/NiNDs@NF electrodes. In total, the whole recovery process of $\mathrm{Ni}$ foam and $\mathrm{Ni}\left(\mathrm{NO}_{3}\right)_{2}$ is simple and environmentally friendly without any emission of toxic gases or wasted energy. All of the above results demonstrate the convenient fabrication and recyclability of the electrodes for practical applications in water electrolysis.

\section{Conclusion}

To construct high-performance, low-cost, and environmentally friendly Ni-based catalytic electrodes for watersplitting, binder-free, heteroatom-free, and recyclable $\mathrm{NiO} /$ 
NiNDs@NF bifunctional catalytic electrodes were fabricated using a one-step quick electrodeposition method. Typically, active Ni nanodot clusters were electrodeposited on $\mathrm{Ni}$ foam in acetonitrile solution. After drying in the air, the $\mathrm{NiO} / \mathrm{NiND}$ composites were obtained, leading to binder-free and heteroatom-free NiO/NiNDs@NF catalytic electrodes, which have superior performance during HER and OER processes. A large-sized $\left(S \sim 70 \mathrm{~cm}^{2}\right)$ catalytic electrode with high durability was also fabricated using this method. Importantly, the recovery process of the raw materials of these electrodes is convenient and environmentally friendly for their recycling use. This method provides a simple and fast technology for preparing recyclable Ni-based bifunctional electrocatalytic materials for large-scale real-world water-splitting electrolyzers.

Acknowledgements H.T. Yu thanks the China and Germany Postdoctoral Exchange Program for this research in HelmholtzZentrum Berlin für Materialien und Energie, the Postdoctoral Science Foundation of China (2017M610324) and NSFC (21704040). The authors also thank the Joint Lab for Structural Research at the Integrative Research Institute for the Sciences (IRIS Adlershof).

Open Access This article is distributed under the terms of the Creative Commons Attribution 4.0 International License (http:// creativecommons.org/licenses/by/4.0/), which permits unrestricted use, distribution, and reproduction in any medium, provided you give appropriate credit to the original author(s) and the source, provide a link to the Creative Commons license, and indicate if changes were made.

Electronic supplementary material The online version of this article (https://doi.org/10.1007/s40820-019-0269-x) contains supplementary material, which is available to authorized users.

\section{References}

1. A.J. Bard, M.A. Fox, Artificial photosynthesis: solar splitting of water to hydrogen and oxygen. ACC Chem. Res. 28, 141-145 (1995). https://doi.org/10.1021/ar00051a007

2. J. Chow, R.J. Kopp, P.R. Portney, Energy resources and global development. Science 302, 1528-1531 (2003). https://doi. org/10.1126/science.1091939

3. J. Turner, G. Sverdrup, M.K. Mann, P.C. Maness, B. Kroposki, M. Ghirardi, R.J. Evans, D. Blake, Renewable hydrogen production. Int. J. Energy Res. 32, 379-407 (2008). https://doi. org/10.1002/er.1372

4. S. Dunn, Hydrogen futures: toward a sustainable energy system. Int. J. Hydrogen Energy 27, 235-264 (2002). https://doi. org/10.1016/S0360-3199(01)00131-8
5. J.D. Holladay, J. Hu, D.L. King, Y. Wang, An overview of hydrogen production technologies. Catal. Today 139, 244-260 (2009). https://doi.org/10.1016/j.cattod.2008.08.039

6. A. Kudo, Y. Miseki, Heterogeneous photocatalyst materials for water splitting. Chem. Soc. Rev. 38, 253-278 (2009). https:// doi.org/10.1039/B800489G

7. N.S. Lewis, D.G. Nocera, Powering the planet: chemical challenges in solar energy utilization. Proc. Natl. Acad. Sci. 103, 15729-15735 (2006). https://doi.org/10.1073/pnas.06033 95103

8. M. Carmo, D.L. Fritz, J. Mergel, D. Stolten, A comprehensive review on PEM water electrolysis. Int. J. Hydrogen Energy 38, 4901-4934 (2013). https://doi.org/10.1016/j.ijhyd ene.2013.01.151

9. Y. Zheng, Y. Jiao, M. Jaroniec, S.Z. Qiao, Advancing the electrochemistry of the hydrogen-evolution reaction through combining experiment and theory. Angew. Chem. Int. Ed. 54, 52-65 (2015). https://doi.org/10.1002/anie.201407031

10. E.A. Hernández-Pagán, N.M. Vargas-Barbosa, T. Wang, Y. Zhao, E.S. Smotkin, T.E. Mallouk, Resistance and polarization losses in aqueous buffer-membrane electrolytes for watersplitting photoelectrochemical cells. Energy Environ. Sci. 5, 7582-7589 (2012). https://doi.org/10.1039/C2EE03422K

11. J. Greeley, T.F. Jaramillo, J. Bonde, I. Chorkendorff, J.K. Nørskov, Computational high-throughput screening of electrocatalytic materials for hydrogen evolution. Mater. Sustain. Energy (2010). https://doi.org/10.1142/9789814317665_0041

12. W. Sheng, M. Myint, J.G. Chen, Y. Yan, Correlating the hydrogen evolution reaction activity in alkaline electrolytes with the hydrogen binding energy on monometallic surfaces. Energy Environ. Sci. 6, 1509-1512 (2013). https://doi.org/10.1039/ C3EE00045A

13. K. Zeng, D. Zhang, Recent progress in alkaline water electrolysis for hydrogen production and applications. Prog. Energy Combust. 36, 307-326 (2010). https://doi.org/10.1016/j. pecs.2009.11.002

14. L. Ji, C. Lv, Z. Chen, Z. Huang, C. Zhang, Nickel-based (photo) electrocatalysts for hydrogen production. Adv. Mater. 30, 1705653 (2018). https://doi.org/10.1002/adma.201705653

15. Y. Fan, Y. Wu, G. Clavel, M.H. Raza, P. Amsalem, N. Koch, N. Pinna, Optimization of the activity of Ni-based nanostructures for the oxygen evolution reaction. ACS Appl. Energy Mater. 1, 4554-4563 (2018). https://doi.org/10.1021/acsae m.8b00666

16. Z.Y. Zhang, S.S. Liu, F. Xiao, S. Wang, Facile synthesis of heterostructured nickel/nickel oxide wrapped carbon fiber: flexible bifunctional gas-evolving electrode for highly efficient overall water splitting. ACS Sustain. Chem. Eng. 5, 529-536 (2017). https://doi.org/10.1021/acssuschemeng.6b01879

17. F. Jing, Q.Y. Lv, J. Xiao, Q.J. Wang, S. Wang, Highly active and dual-function self-supported multiphase $\mathrm{NiS}-\mathrm{NiS}_{2}-\mathrm{Ni}_{3} \mathrm{~S}_{2} /$ $\mathrm{NF}$ electrodes for overall water splitting. J. Mater. Chem. A 6 , 14207-14214 (2018). https://doi.org/10.1039/C8TA03862G

18. L. Guang, D.Y. He, R. Yao, Y. Zhao, J.P. Li, Amorphous $\mathrm{NiFeB}$ nanoparticles realizing highly active and stable oxygen 
evolving reaction for water splitting. Nano Res. 11, 1664-1675 (2018). https://doi.org/10.1007/s12274-017-1783-0

19. G. Liu, D.Y. He, R. Yao, Y. Zhao, J.P. Li, Enhancing the water oxidation activity of $\mathrm{Ni}_{2} \mathrm{P}$ nanocatalysts by iron-doping and electrochemical activation. Electrochim. Acta 253, 498-505 (2017). https://doi.org/10.1016/j.electacta.2017.09.057

20. Z.Z. Ma, H.J. Meng, M. Wang, B. Tang, J.P. Li, X.G. Wang, Porous $\mathrm{Ni}-\mathrm{Mo}-\mathrm{S}$ nanowire network film electrode as a high-efficiency bifunctional electrocatalyst for overall water splitting. ChemElectroChem 5, 335-342 (2018). https://doi. org/10.1002/celc.201700965

21. Z.Z. Ma, R.X. Li, M. Wang, H.J. Meng, F. Zhang, X.-Q. Bao, B. Tang, Self-supported porous Ni-Fe-P composite as an efficient electrocatalyst for hydrogen evolution reaction in both acidic and alkaline medium. Electrochim. Acta 219, 194-203 (2016). https://doi.org/10.1016/j.electacta.2016.10.004

22. H.J. Meng, W.J. Zhang, Z.Z. Ma, F. Zhang, B. Tang, J.P. Li, X.G. Wang, Self-supported ternary Ni-S-Se nanorod arrays as highly active electrocatalyst for hydrogen generation in both acidic and basic media: experimental investigation and DFT calculation. ACS Appl. Mater. Interfaces 10, 2430-2441 (2018). https://doi.org/10.1021/acsami.7b14506

23. Z.Z. Ma, Q. Zhao, J.P. Li, B. Tang, Z.H. Zhang, X.G. Wang, Three-dimensional well-mixed/highly-densed NiS-CoS nanorod arrays: an efficient and stable bifunctional electrocatalyst for hydrogen and oxygen evolution reactions. Electrochim. Acta 260, 82-91 (2018). https://doi.org/10.1016/j.elect acta.2017.11.055

24. H. Bates, C. Richardson, Nickel and sustainability: towards a circular economy. Nickel Magazine 33, 2 (2018). https://www. nickelinstitute.org/library/articles/nickel-magazine-33-2-trans lated. Accessed Sept 2018.

25. M. Gong, W. Zhou, M.-C. Tsai, J. Zhou, M. Guan et al., Nanoscale nickel oxide/nickel heterostructures for active hydrogen evolution electrocatalysis. Nat. Commun. 5, 4695 (2014). https://doi.org/10.1038/ncomms5695

26. H. Lai, Q. Wu, J. Zhao, L. Shang, H. Li, R. Che, Z. Lyu, J. Xiong, L. Yang, X. Wang, Mesostructured NiO/Ni composites for high-performance electrochemical energy storage. Energy Environ. Sci. 9, 2053-2060 (2016). https://doi.org/10.1039/ C6EE00603E

27. Y. Zeng, Y. Meng, Z. Lai, X. Zhang, M. Yu, P. Fang, M. Wu, Y. Tong, X. Lu, An ultrastable and high-performance flexible fiber-shaped $\mathrm{Ni}-\mathrm{Zn}$ battery based on a $\mathrm{Ni}-\mathrm{NiO}$ heterostructured nanosheet cathode. Adv. Mater. 29, 1702698 (2017). https://doi.org/10.1002/adma.201702698

28. J. Xiao, Z.Y. Zhang, Y. Zhang, Q.Y. Lv, F. Jing, K. Chi, S. Wang, Large-scale printing synthesis of transition metal phosphides encapsulated in N, P co-doped carbon as highly efficient hydrogen evolution cathodes. Nano Energy 51, 223-230 (2018). https://doi.org/10.1016/j.nanoen.2018.06.040

29. G. Liu, R. Yao, Y. Zhao, M.H. Wang, N. Li, Y.B. Li, X. Bo, J.P. Li, C. Zhao, Encapsulation of $\mathrm{Ni} / \mathrm{Fe}_{3} \mathrm{O}_{4}$ heterostructures inside onion-like $\mathrm{N}$-doped carbon nanorods enables synergistic electrocatalysis for water oxidation. Nanoscale 10, 39974003 (2018). https://doi.org/10.1039/C7NR09446A
30. Y.B. Li, X. Tan, S. Chen, X. Bo, H.J. Ren, S.C. Smith, C. Zhao, Processable surface modification of nickel-heteroatom $(\mathrm{N}, \mathrm{S})$ bridge sites for promoted alkaline hydrogen evolution. Angew. Chem. Int. Ed. 131, 471-476 (2019). https://doi. org/10.1002/ange.201808629

31. Q. Zhang, H.X. Zhong, F.L. Meng, D. Bao, X.B. Zhang, X.L. Wei, Three-dimensional interconnected $\mathrm{Ni}(\mathrm{Fe}) \mathrm{O}_{x} \mathrm{H}_{y}$ nanosheets on stainless steel mesh as a robust integrated oxygen evolution electrode. Nano Res. 11, 1294-1300 (2018). https://doi.org/10.1007/s12274-017-1743-8

32. G. Liu, X.S. Gao, K.F. Wang, D.Y. He, J.P. Li, Uniformly mesoporous $\mathrm{NiO} / \mathrm{NiFe}_{2} \mathrm{O}_{4}$ biphasic nanorods as efficient oxygen evolving catalyst for water splitting. Int. J. Hydrogen Energy 41, 17976-17986 (2016). https://doi.org/10.1016/j. ijhydene.2016.07.268

33. M. Wang, W.J. Zhang, F.F. Zhang, Z.H. Zhang, B. Tang, J.P. Li, X.G. Wang, Theoretical expectation and experimental implementation of in situ Al-doped $\mathrm{CoS}_{2}$ nanowires on dealloying-derived nanoporous intermetallic substrate as an efficient electrocatalyst for boosting hydrogen production. ACS Catal. 9, 1489-1502 (2019). https://doi.org/10.1021/ acscatal.8b04502

34. Y.-L. Zhu, Y. Katayama, T. Miura, Effects of acetonitrile on electrodeposition of $\mathrm{Ni}$ from a hydrophobic ionic liquid. Electrochim. Acta 55, 9019-9023 (2010). https://doi.org/10.1016/j. electacta.2010.07.097

35. H. Yu, Y. Li, X. Li, L. Fan, S. Yang, Electrochemical preparation of $\mathrm{N}$-doped cobalt oxide nanoparticles with high electrocatalytic activity for the oxygen-reduction reaction. Chem. Eur. J. 20, 3457-3462 (2014). https://doi.org/10.1002/ chem.201303814

36. H. Yu, Y. Li, X. Li, L. Fan, S. Yang, Highly dispersible and charge-tunable magnetic $\mathrm{Fe}_{3} \mathrm{O}_{4}$ nanoparticles: facile fabrication and reversible binding to GO for efficient removal of dye pollutants. J. Mater. Chem. A 2, 15763-15767 (2014). https ://doi.org/10.1039/C4TA03476G

37. M. Yu, W. Wang, C. Li, T. Zhai, X. Lu, Y. Tong, Scalable self-growth of Ni@NiO core-shell electrode with ultrahigh capacitance and super-long cyclic stability for supercapacitors. NPG Asia Mater. 6, e129 (2014). https://doi.org/10.1038/ am.2014.78

38. Y. Li, X. Li, Z. Wang, H. Guo, T. Li, One-step synthesis of Li-doped $\mathrm{NiO}$ as high-performance anode material for lithium ion batteries. Ceram. Int. 42, 14565-14572 (2016). https://doi. org/10.1016/j.ceramint.2016.06.071

39. T. Hou, L. Yuan, T. Ye, L. Gong, J. Tu, M. Yamamoto, Y. Torimoto, Q. Li, Hydrogen production by low-temperature reforming of organic compounds in bio-oil over a CNT-promoting Ni catalyst. Int. J. Hydrogen Energy 34, 9095-9107 (2009). https ://doi.org/10.1016/j.ijhydene.2009.09.012

40. Q. Lu, M.W. Lattanzi, Y. Chen, X. Kou, W. Li et al., Supercapacitor electrodes with high-energy and power densities prepared from monolithic $\mathrm{NiO} / \mathrm{Ni}$ nanocomposites. Angew. Chem. Int. Ed. 123, 6850-6979 (2011). https://doi. org/10.1002/ange.201101083 
41. J.W. Weidner, P. Timmerman, Effect of proton diffusion, electron conductivity, and charge-transfer resistance on nickel hydroxide discharge curves. J. Electrochem. Soc. 141, 346351 (1994). https://doi.org/10.1149/1.2054729

42. N. Liu, J. Li, W. Ma, W. Liu, Y. Shi et al., Ultrathin and lightweight 3D free-standing $\mathrm{Ni@} \mathrm{NiO} \mathrm{nanowire} \mathrm{membrane} \mathrm{elec-}$ trode for a supercapacitor with excellent capacitance retention at high rates. ACS Appl. Energy Mater. 6, 13627-13634 (2014). https://doi.org/10.1021/am503108x

43. Y.-G. Wang, Y.-Y. Xia, Electrochemical capacitance characterization of $\mathrm{NiO}$ with ordered mesoporous structure synthesized by template SBA-15. Electrochim. Acta 51, 3223-3227 (2006). https://doi.org/10.1016/j.electacta.2005.09.013

44. Y.-J. Huang, C.-H. Lai, P.-W. Wu, L.-Y. Chen, Ni inverse opals for water electrolysis in an alkaline electrolyte. J. Electrochem. Soc. 157, 18-22 (2010). https://doi.org/10.1149/1.3281332

45. E.J. Popczun, J.R. McKone, C.G. Read, A.J. Biacchi, A.M. Wiltrout, N.S. Lewis, R.E. Schaak, Nanostructured nickel phosphide as an electrocatalyst for the hydrogen evolution reaction. J. Am. Chem. Soc. 135, 9267-9270 (2013). https:// doi.org/10.1021/ja403440e

46. T.-W. Lin, C.-J. Liu, C.-S. Dai, $\mathrm{Ni}_{3} \mathrm{~S}_{2}$ /carbon nanotube nanocomposite as electrode material for hydrogen evolution reaction in alkaline electrolyte and enzyme-free glucose detection. Appl. Catal. B: Environ. 154, 213-220 (2014). https:// doi.org/10.1016/j.apcatb.2014.02.017

47. S. Baranton, C. Coutanceau, Nickel cobalt hydroxide nanoflakes as catalysts for the hydrogen evolution reaction. Appl. Catal. B: Environ. 136, 1-8 (2013). https://doi.org/10.1016/j. apcatb.2013.01.051

48. T. Sun, C. Zhang, J. Chen, Y. Yan, A.A. Zakhidov, R.H. Baughman, L. Xu, Three-dimensionally ordered macro-/ mesoporous $\mathrm{Ni}$ as a highly efficient electrocatalyst for the hydrogen evolution reaction. J. Mater. Chem. A 3, 1136711375 (2015). https://doi.org/10.1039/C5TA01383F

49. L.-A. Stern, L. Feng, F. Song, $\mathrm{X}$. Hu, $\mathrm{Ni}_{2} \mathrm{P}$ as a Janus catalyst for water splitting: the oxygen evolution activity of $\mathrm{Ni}_{2} \mathrm{P}$ nanoparticles. Energy Environ. Sci. 8, 2347-2351 (2015). https:// doi.org/10.1039/C5EE01155H
50. D. Liu, Q. Lu, Y. Luo, X. Sun, A.M. Asiri, $\mathrm{NiCo}_{2} \mathrm{~S}_{4}$ nanowires array as an efficient bifunctional electrocatalyst for full water splitting with superior activity. Nanoscale 7, 15122-15126 (2015). https://doi.org/10.1039/C5NR04064G

51. M. Ledendecker, S. Krick Calderón, C. Papp, H.P. Steinrück, M. Antonietti, M. Shalom, The synthesis of nanostructured $\mathrm{Ni}_{5} \mathrm{P}_{4}$ films and their use as a non-noble bifunctional electrocatalyst for full water splitting. Angew. Chem. Int. Ed. 127, 12365-12538 (2015). https://doi.org/10.1002/ange.201502438

52. Q. Liu, S. Gu, C.M. Li, Electrodeposition of nickel-phosphorus nanoparticles film as a Janus electrocatalyst for electrosplitting of water. J. Power Sources 299, 342-346 (2015). https ://doi.org/10.1016/j.jpowsour.2015.09.027

53. J. Shi, J. Hu, Y. Luo, X. Sun, A.M. Asiri, $\mathrm{Ni}_{3} \mathrm{Se}_{2}$ film as a nonprecious metal bifunctional electrocatalyst for efficient water splitting. Catal. Sci. Technol. 5, 4954-4958 (2015). https:// doi.org/10.1039/C5CY01121C

54. T. Liu, Q. Liu, A.M. Asiri, Y. Luo, X. Sun, An amorphous CoSe film behaves as an active and stable full water-splitting electrocatalyst under strongly alkaline conditions. Chem. Commun. 51, 16683-16686 (2015). https://doi.org/10.1039/ C5CC06892D

55. L.-L. Feng, G. Yu, Y. Wu, G.-D. Li, H. Li, Y. Sun, T. Asefa, W. Chen, $\mathrm{X}$. Zou, High-index faceted $\mathrm{Ni}_{3} \mathrm{~S}_{2}$ nanosheet arrays as highly active and ultrastable electrocatalysts for water splitting. J. Am. Chem. Soc. 137, 14023-14026 (2015). https://doi. org/10.1021/jacs.5b08186

56. J. Luo, J.-H. Im, M.T. Mayer, M. Schreier, M.K. Nazeeruddin, N.-G. Park, S.D. Tilley, H.J. Fan, M. Grätzel, Water photolysis at $12.3 \%$ efficiency via perovskite photovoltaics and Earthabundant catalysts. Science 345, 1593-1596 (2014). https:// doi.org/10.1126/science.1258307

57. W. Zhu, X. Yue, W. Zhang, S. Yu, Y. Zhang, J. Wang, J. Wang, Nickel sulfide microsphere film on $\mathrm{Ni}$ foam as an efficient bifunctional electrocatalyst for overall water splitting. Chem. Commun. 52, 1486-1489 (2016). https://doi.org/10.1039/ C5CC08064A 